\title{
Malverde: de Santo familiar a protector de narcotraficantes
}

\section{Armando Partida Tayzan}

A la maestra Olga Harmony

A "Jesús Malverde", uno más de los legendarios héroes populares mexicanos de principios del siglo XX, émulo del Robin Hood de todos los pueblos necesitados de héroes protectores ante la opresión de la clase dominante, lo convirtió el dramaturgo Oscar Liera en vindicador de las causas de los pobres y necesitados de auxilio en su obra El jinete de la divina Providencia (1984). ${ }^{1}$

En tanto 24 años después, Alejandro Román presenta reloaded a este héroe popular en Malverde, día de la Santa Cruz (2008), como protector de narcotraficantes y/o narcoterroristas; protagonistas de sus obras dramáticas más recientes, con las cuales ha ganado varios premios nacionales en concursos de dramaturgia. ${ }^{2}$

Esther Seligson escribió en su presentación a la primera publicación del Jinete de la Divina Providencia: "Unir los sueños, juntar los juegos", refiriéndose a una de las particularidades lúdicas de la escritura dramática de Liera, y sobre los héroes míticos, en particular sobre Malverde:

[...] En El jinete de la Divina Providencia, por ejemplo Malverde va a concretizar la necesidad del pueblo por romper su ya insostenible situación; campesinos despojados de sus tierras, peones explotados, a quienes el patrón mata impunemente; injusticia, arbitrariedad, pobreza y hambre, juegos del Poder en manos de gobernantes y autoridades que no basta con denunciar, sino que hay que anular, que hacer estallar en pedazos. "Yo creo que en esa época todos eran Malverde", 4 una realidad social y a jugar el todo por el todo para recobrar su dignidad y pureza. Así, cada personaje en ese Culiacán de las maravillas ${ }^{5}$ va a vivir en carne propia lo que le ocurre al Héroe, que terminará por 
transformarse, ya muerto, más que en una leyenda, en parte de la personalidad, de los recuerdos, y de las necesidades de cada quien: "Venerar a Malverde es como desafiar a los malos gobernantes", una manera de perpetuar la rebeldía, el derecho a decirlo NO al statu quo, a la fatalidad. (Supl.)

En tanto Sonia Sierra en sus consideraciones sobre el estreno de Malverde de Alejandro Román reseña que:

Malverde, la nueva obra de teatro de Art Narcó Producciones, transcurre en la así llamada capilla sixtina del crimen organizado, situada en Culiacán, a donde llega un trío norteño - todos los personajes son idénticos a Malverde. Los hechos se producen en el día de la Santa Cruz, tres de mayo, fecha en la que supuestamente murió el que es conocido como el santo de los narcos.

$[\ldots]$

Con esta obra Román traza una cartografía contemporánea del narcotráfico: los personajes sin diálogos entre sí, representan tres historias que resumen lo que se vive en este mundo: la soledad y vacío que enfrenta un gran capo, los errores de un policía infiltrado en el narco y que era el guardaespaldas de "Rodolfillo" y la venganza que persigue todo sicario.

[...]

Los personajes de su nueva obra - tres escalas de la estructura del narcotráfico - acuden a la capilla de Malverde a presentar su agradecimiento por los favores y milagros que han recibido. (F3)

Es obvio señalar que en estas dos obras nos encontramos ante una cuestión que va más allá de las propuestas dramatúrgicas, de un mero modelo de acción dramática, ante la resignificación del rol social del personaje, que al transformarse modifica por igual al rito correspondiente al mito del bandido generoso y, con ello, la ritualidad y la liturgia populares. Como fuera señalado por la crítica teatral Olga Harmony, quien al comparar ambas obras señalara en un artículo:

[...] Malverde era un santo familiar al que se encomendaban las personas trabajadores y buenas.

Ahora es protector de narcos. Es posible que muchos de ellos se identifiquen con su patrono, al brindar protección a muchas personas, apadrinar niños, ofrecer las famosas "narcolimosnas" de las que mucho se habla y poco se demuestra. $\left(6^{\mathrm{a}}\right)$

Y más adelante: 
[...] La obra de Román está compuesta, a decir de la investigadora [Rocío Galicia], ${ }^{6}$ como un corrido en el que se da por sentado, de una buena vez, que Jesús Malverde es el santo patrono de los narcotraficantes, sin explicar el tránsito de bandido generoso impugnador de los desmanes cometidos por los poderosos a este estado en que protege y casi beatifica al horrendo negocio del narcotráfico. $\left(6^{\mathrm{a}}\right)$

Al respecto trataremos de dilucidar cuál ha sido ese paso dramatúrgico de resignificación del protagonista en ambas obras, independiente de las propias consideraciones de carácter socio-económico y político con los que obviamente se encuentra estrechamente relacionado el nuevo rol social de Malverde, y por qué no, ideológico y religioso, que representa en la actualidad la figura del bandido generoso en cuestión. Valiéndonos para ello del estudio liminar de Heriberto Yépez, incluido en la antología Ánimas y Santones, compilada por Rocío Galicia y en la cual se incluye el Malverde de Román, que trata sobre "El ciclo inconcluso del mito", en la entrada al "desierto fronterizo"; porque indudablemente nos estamos refiriendo al teatro del norte, al teatro de la frontera norte. Estudio en el que destaca en primer lugar la cuestión del narratema, sobre el cual nos dice:

[...] Un narratema se caracteriza porque está hecho de ruinas, pedazos, lagunas. El narratema todavía no tiene coherencia. Su incongruencia es, justamente, su poder magnético.

Con el detritus del narratema podrán componerse varias versiones, narraciones múltiples que en su diversidad inverosímil, tergiversación disímil o chismerío contundente, remitirá, ineludiblemente, al narratema, caso iniciático. El narratema es desorden.

$[\ldots]$

La cultura es pseudosistema. Un rompecabezas cuyas piezas parecen encajar perfectamente entre sí, hasta que se observa más de cerca y advertimos que existen piezas (narratemas) que están hechos [sic], a su vez de piezas que no embonan, piezas en cuya estructura faltan subpiezas, acaece desintegración, dinámica diabólica. (cit. en Galicia 4-5)

Una vez expuesto el narratema, Yépez enfoca la cuestión de la "Épica y el mito", en el que destaca que:

[...] El narratema se vuelve mito para dar sentido a una existencia. El mito, al reiterarse, se vuelve trabajo. Da continuidad. Un relato es mito si procura enraizar y dirigir al individuo dentro de su cultura. El mito es completud. 
Para luego pasar a la concepción del héroe del narratema, del mito:

El héroe es un ser desmembrado. No encaja. Ni se ha reconocido. El héroe se experimenta a sí mismo como un ser inconcluso, cuya completud sólo puede ser logrado a través de la gran hazaña.

El héroe, antes de vencer, no ha podido desprenderse. No se ha completado. Sigue siendo un ser dependiente, sobajado, maltratado, irreconocido, despreciado, marginado, expulsado.

El héroe es aquel que quiere ser sí mismo. Pero está dividido.

El héroe es nuestra herida. (cit. en Galicia 8)

En tanto ya sobre el Santo considera, respecto al santo popular, que éste conserva empero:

[...] más vivamente los rasgos de lo épico. Al no tratarse de santos puramente místicos — que se han vuelto seres contemplativos, religiosamente pasivos - , el santo popular frecuentemente es un criminal, un forajido, un ser ambivalente, sospechoso de maldad. El santo popular guarda muchos rasgos del héroe. Se trata de una negociación entre colonialismo judeo cristiano y supervivencia de mundos mágicos paganos.

\section{$[\ldots]$}

El poder que tiene el héroe y que en el santo se debilitó (para prevenirle volverse "malvado"), se le restablece cuando ya está muerto. No se trata ya de un poder de hazaña propia sino de milagro concedido al necesitado. En el santo se intenta restablecer la economía de la energía que había sido lesionada por lo valores debilitantes del judeocristianismo. El santo milagroso, ya muerto, da la energía que le faltó, cuando vivo, para que otros completen lo que él dejó pendiente. (cit. en Galicia 10-11)

Un estudio y análisis dramatúrgico sobre ambas obras nos puede auxiliar al respecto.

\section{El Jinete de la Divina Providencia}

Si bien el texto dramático de Óscar Liera resulta estilísticamente singular como obra literaria, para nuestro propósito sólo consideraremos la fábula y la trama con las que construyera su Malverde del Jinete de la Divina Providencia. Dos son los narratemas de donde parte el autor: el referido al mito del bandido generoso sinaloense en vida y sus acciones como tal, hasta su muerte, y al mito religioso posterior a su muerte, popularizado a mediados de los años cincuenta y reforzado un par de decenios después. 
Al primero lo convirtió en la leyenda de un héroe popular que robara, asaltara, despojara, a los principales de la región, inscritos históricamente en plena dictadura del porfiriato; identificándolos Liera en su texto dramático con los apellidos reales, ${ }^{7}$ junto con de su principal impugnador el Gobernador Cañedo. ${ }^{8}$ Mismos que en la metaficcionalidad del texto dramático ofrecieran gran recompensa por denunciarlo, al burlar éste siempre la acordada.

El segundo es el relacionado con su muerte que, según la versión más difundida, fuera traicionado por un compadre, quien le cortase las piernas para que no huyera, en tanto lo denunciaba para recibir la recompensa. Sin embargo Malverde logró arrastrarse hasta un cruce de camino donde se le encontrase y fuese colgado, no sin antes haber lanzado Cañedo la amenaza de castigar a quien se atreviese a darle sepultura. Con el correr del tiempo y de los embates de los fenómenos naturales la soga se rompería y caerían los huesos, permaneciendo éstos insepultos, hasta que un campesino habiendo perdido un becerro lo invocó acudiese en su ayuda, ofreciéndole colocar una piedra encima de los restos. Al efectuar la promesa y darse vuelta, el becerro estaba junto al campesino. Así comenzó el pueblo a darle sepultura a los huesos del bandido.

De allí el inicio de la mitificación del héroe, convertido en benefactor de quien lo invocase; lo que condujo consecuentemente a erigirle una ermita sobre el túmulo de piedras ofrendadas por haber respondido a las súplicas de los menesterosos, o necesitados de ayuda.

El siguiente paso religioso lo propiciaron involuntariamente las autoridades estatales, quienes decidieron construir un edificio gubernamental precisamente en ese cruce de caminos, donde se encontraba la ermita, ya en plena zona urbana de la ciudad de Culiacán; desplazándola para ello a un costado, tomando su distancia.

La protesta popular no se hizo esperar, llegando a amenazar al orden público el movimiento en protesta por la acción tomada por las autoridades estatales. Razón por la cual el propio gobierno construyó lo que hoy se conoce como la capilla de Malverde, en el sitio a donde fuese desplazado.

La intención de Liera no fue la de revalorar la figura del bandido generoso, sino el de hablar del presente, del gobernador Toledo Corro ${ }^{9}$ a través de la metaforización del entonces estado de cosas, efectuando un paralelismo con los tiempos contemporáneos y las formas de gobernar, por una parte; en tanto por otra, se muestra la necesidad de nuevos héroes, de nuevos santones defensores del pueblo. 
A partir de la devoción rendida por la población, que desembocara en el culto a Malverde, surgió un nuevo constructo cultural. El del bandido de los ricos para ayudar a los pobres, quien incursionara en el Culiacán de principios del siglo XX, cubierto por largas y verdes hojas de plátano, para pasar desapercibido por las noches en la oscuridad de las calles al asaltar, y confundirse con la vegetación del monte al huir. De allí el mote de "allí viene el mal verde", que deviniera en Malverde; mismo que no corresponde a apellido alguno, según las especulaciones.

MARTHA. ¡Pues sí, cómo no! ¡Malverde! Yo siempre que puedo hablar de sus milagros lo hago porque tengo mucho que agradecerle. Yo no lo conocí personalmente, por supuesto; él murió a fines del siglo pasado; pero cuando yo estaba joven conocí a una viejita que me contó la historia; ella era una chamaca cuando lo mataron, me decía incluso que fue al monte a ver el cadáver. Malverde, como ya se ha dicho aquí muchas veces, robaba para los pobres; en esa época Culiacán no era tan grande, todo eso donde ahora es su tumba era un monte de bainoros, ${ }^{10}$ por allí pasaba el camino que iba para la costa, para Navolato, Aguaruto, Badirahuato, La Pipima, ${ }^{11}$ por allí llegaban los lecheros y los queseros que venían al mercado de Culiacán a vender sus cosas; y por allí había un mezquite que tenía una rama que cruzaba el camino. ${ }^{12}$ Pues Malverde era un hombre muy hábil, cuando los rurales creían que lo tenían cercado ya estaba haciendo otra de las suyas. Recuerdo que contaba la señora que una vez que lo perseguían los rurales llegó y se metió en la fábrica de hilados y a los cuales ya les había robado. Pero don Diego Redo ${ }^{13}$ era un hombre muy recto y salió y les dijo cuando querían entrar: "No, señores, ustedes aquí no pueden entrar a apresarlo; si él ha buscado asilo aquí, aquí lo tiene; agárrenlo, si quieren, cuando salga; pero aquí tiene mi protección". Y allí se quedaban los rurales esperándolo días enteros, pero quién sabe cómo se les huía y cuando los rurales dejaban el lugar era porque les avisaban que Malverde ya había robado en otra parte. PADRE JAVIER. Es, señora, y lo cual le agradecemos, muy interesante su conversación; pero nosotros, en nuestro procedimiento, quisiéramos oír primero los milagros que le ha obrado el ánima de Malverde y luego, sí, claro, conocer lo que sabe usted de su historia. (362-63)

Proceso mitificador que Óscar Liera siguiera paso a paso, hasta plantearlo dramáticamente como un hecho histórico, como correspondería 
a su propio artefacto dramático, surgido de la simbolización del imaginario colectivo sobre este héroe popular, devenido en santón.

Si bien su reclamo político a las autoridades, al igual que al gran capital, Liera lo metaforiza narrativamente, su anticlericalismo - por el contrario - , lo hizo sentir de manera evidente y notoria, al igual que en Cúcara y Mácara, al actualizar la línea dramática del mito del Malverde santón, junto con el mito del héroe legendario.

Para ello se valió de una construcción dramática determinada por la trama al crear dos líneas de acción que se imbrican y retroalimentan, constituyendo dos correlatos espacio-temporales, como manifestación de dos procesos socioculturales; recurriendo para ello a la simbolización de ambos en el imaginario regional. Una externa determinada espacio-temporalmente por el presente en la que, a manera de un proceso de beatificación, los representantes de la iglesia analizan y reconstruyen la hagiografía popular sobre la vida y milagros atribuidos a Malverde, y otra interna en la que se nos presentan las hazañas del héroe y su lucha contra el estado de cosas; ambas del todo ficcionales:

PADRE JOSÉ. ¿Le reza usted oraciones?

MARTHA. No, para qué; él goza de Dios, él no quiere oraciones, quiere piedras. Yo creo que venerar a Malverde es como una forma de desafiar a los malos gobernantes. Le llevamos veladoras y música, le gusta mucho la tambora y que uno vaya a echarse sus cervecitas ${ }^{14}$ allí. OBISPO. Pero eso no tiene nada que ver con nuestra realidad católica. MARTHA. ¿Qué es lo que no tiene que ver? En la iglesia tocan música y se canta y se consagra el vino.

PADRE JAVIER. Es otra cosa diferente.

MARTHA. Claro que es diferente. Malverde ayudó a los pobres, estuvo al lado de ellos. Aquí, el obispo sólo va a desayunar a la casa de los ricos. Además, la música que le gusta a Malaverde es la música que nos gusta a todos. Decía mi abuela que tenemos el equilibrio dentro de la oreja y que la gente que oía música bonita nunca perdía el sentido, ni el rumbo. En la época de Malverde, el gobernador Cañedo, que era un bandido, le encantaba la música; una vez dijo en la plaza que cuando él se muriera quería que lo enterraran con el "El niño perdido". ${ }^{15}$ (Liera 365)

Niño perdido, que como ritornelo amenazante se escucha a todo lo largo de la pieza para atemorizar a Cañedo, al haber expresado este personaje 
histórico dicho deseo; en el que sintetizara Liera el miedo de toda la clase dominante de la época ante la figura de Malverde:

ADELA. ¡Cállate, tonto! y no andes asustando a las gentes con tus mentiras y tus cuentos.

HILARIO. ${ }^{16}$ Mentiras, cuentos... a la gente no le gusta la verdad, Adela; la verdad es como el limón en los ojos, arde mucho, pero luego los abre más y se ve más claro. (Ríe.) Mira lo que pasa, Adela, mira bien lo que pasa.

ADELA. Yo sólo veo lo que quiero ver, Hilario.

HILARIO. El sol no camina, Adela. Lleva muchas horas parado. No mires lo que quieres, sino lo que pasa; esta noche vendrá el diablo verde por aquí por la casa.

ADELA. ¡Cállate ya, Hilario!, ¿no ves que está enfermo y tiene miedo?; tiene el mal del miedo metido en todos los huesos.

HILARIO. Así dijeron ayer por la mañana en el mercado, que dejó un letrero en la amapa ${ }^{17}$ blanca; que esta noche, a la hora del calor fuerte, cuando las tochis ${ }^{18}$ se haigan encerrado en sus agujeros y de tan oscuro no se ven ni las manos, vendría para aclarar la muerte del Julián.

ADELA. Por la tarde van a venir los de la acordada a vigilar la casa, ya está todo arreglado.

HILARIO. Esos son los que tienen más miedo, llevan años y años buscando al diablo verde y no lo hallan, es un mal verde el que viene, Adela. (Ríe.) Muchas cosas malas van a pasar y tú lo sabes, muchas cosas malas van a entrar en las casas de los ricos, Adela. (Se va riendo y rumiando las últimas palabras.). (367-68)

Y más adelante, en el acto adivinatorio de los mentalistas: Obdulio Pacheco y el Polidor: ${ }^{19}$

Entre ellos se mezcla gente del pueblo y se repite la misma escena con que terminó el primer acto; es el mismo cuadro plástico. Cañedo vacía la bolsa de monedas de oro frente a Obdulio.

CAÑEDO. ¿Quién es y dónde se esconde Malverde?

OBDULIO. Malverde no se esconde; ustedes no quieren verlo.

CAÑEDO. ¿Quién es Malverde? (Obdulio se quita la venda, se le queda viendo muy fijamente.)

OBDULIO. Soy yo. (Se carcajea, saca un puñal y se lo entierra en el corazón a Cañedo. Se oye "El niño perdido", se va haciendo el oscuro, por otro lado entra Adela con una lámpara encendida. Llega 
hasta Cañedo, quien está en la tina completamente desnudo como en la primera escena.). (390)

El entramado de tiempos y espacios: el interno, y el externo del presente de la indagación de la Iglesia con los informantes, más que plantear la beatificación del héroe, es el medio del que se sirve el autor para contarnos la historia del espacio tiempo interno, a la que hacen referencia los participantes de la indagación al exponer en primera instancia los milagros realizados por éste y de los cuales ellos han sido testigos; en tanto que al mismo tiempo rememoran los usos y costumbres durante el gobierno de Cañedo; estableciendo así el paralelismo con los tiempos presentes, en los que Toledo Corro fuese el gobernante del estado de Sinaloa; todo ello amalgamado hábilmente por Liera:

ADELA. (lo mueve para despertarlo). Don Francisco, don Francisco, ¿se quedó dormido?

CAÑEDO. Adela, Adela, tengo tanto miedo, allí en el centro de la plaza y nadie hizo nada. ¿Por qué el pueblo no ama a sus gobernantes? ADELA. (siempre seca.) Yo amo a mis gobernantes. (Para ella.) Ya andan acercando otra vez "El niño perdido", desde que dijo que quería que con esa pieza lo enterraran, se lo echan cada noche por la ventana. (Al hombre que salió.) ¡Ya cabrones, que todo lo que buscan les salga al revés! (391)

De allí que el dramaturgo se valiera de la mitificación del bandido generoso, iniciada en la segunda mitad del siglo XX, misma que iría progresivamente en aumento conforme se agudizaran las crisis económicas y el abuso de poder por parte del partido hegemónico; por lo que el pueblo recurriría - al igual que la clase media y uno que otro empresario en apuros financieros - a la figura de Malverde para que éste intercediera a su favor; tornándose así en santo patrimonial, como una expresión más de la religión popular regional. ${ }^{20}$ Religión basada en milagros: sanaciones divinas de enfermedades, lesiones o heridas; al igual que en la resolución de problemas personales, familiares, económicos, de negocios y demás:

OBISPO. Espero que con lo que hemos oído les resulte suficiente y sirva para que no me digan autoritario, impositivo y quien sabe cuántas cosas más. Ya les cumplí el caprichito de estar en estas reuniones. Creo que se han convencido de que no es tan fácil iniciar un proceso de beatificación. ¿Se imaginan ustedes si presentamos el material recopilado hasta ahora? La congregación de ritos en Roma nos destituye a todos de nuestros cargos por ineptos. 
PADRE JAVIER. Pero es una realidad, una misteriosa realidad mística, mágica y social.

PADRE JOSÉ. Supongo que todos estamos convencidos de que en la actualidad tenemos que ser más prácticos que teóricos.

OBISPO. Pero si Culiacán no ha sido más que un pueblo de locos. (384)

Razón por lo cual Malverde no puede ser canonizado como el Jinete de la Divina Providencia.

\section{Malverde}

Alejandro Román, a su vez, vuelve los ojos a Malverde a más de dos décadas después de la escritura del Jinete de la Divina Providencia, cuando la situación social del país se ha agudizado tanto, que la violencia ha venido a sentar sus reales; pasando el narratema sobre este personaje a un segundo plano - aunque referente primordial - al centrar el autor el desarrollo de la acción dramática en el discurrir del pensamiento de los protagonistas sobre sus conflictos personales, como consecuencia de su participación activa en el narcotráfico.

De manera que la narración monológica de éstos encubre la fábula y la trama, desarrolladas en el presente, imbricadas en el pasado, en un ir y venir del relato de la prehistoria de los tres protagonistas reunidos en la capilla del santón:

JULIO: Hijo desobediente y rival de su padre narco, quien ambicionando operar por sí mismo, es condenado a muerte por el padre, salvándolo Malverde, a quien invocase en esa situación; quien además milagrosamente lo relacionase con los "colombianos" y los "gallos" militares, y del gobierno, coludidos con el narcotráfico.

GAVILÁN: ex militar, sicario de un capo, sobreviviente de un ajuste de cuentas, resulta finalmente asesinado por el mismo pistolero, quien anteriormente lo dejase agonizante.

LEONEL: Narco, a quien Julio le ha asesinado a dos hermanos, solicita al santo Patrón: Malverde bendecirle sus balas para cobrar vengarse por la muerte de éstos, para ajustar cuentas con el capo responsable de ello: Julio.

Ier TIEMPO

RELATO: fragmentado, individual; cómo Malverde les ha salvado la vida y ha propiciado el éxito de sus carreras delictuosas. II $^{\circ}$ TIEMPO 
RELATO: pasado presente: Las causas de lo narrado en el primer tiempo: prehistoria.

Exposición de movimientos operativos de los narcos — lo marcado por el destino.

IIIer TIEMPO

RELATO:

GAVILAN: su prehistoria como ex Policía Fiscal de Aduanas. Posteriormente convertido en sicario encubierto como pistolerillo de poca monta para no llamar la atención de los capos y de la DEA, que "anda" tras él, al igual que de los capos de otro cártel del Pacífico, en contubernio con las autoridades.

Éste presiente su muerte, y rememora como fuese herido mortalmente, al ser asesinado un hijo del capo a quien sirviera, por "cosas de política sinaloense"; en la lucha por el poder. Transición al momento en cuestión ese 3 de mayo.

LEONEL: 1) Llega a la capilla con un ramo de rosas el día de la santa cruz, durante el festejo del "santo". La capilla es cercada por 40 pistoleros de la escolta de Julio. La mirada del santo le tranquiliza. IIIer TIEMPO

JULIO: Lentes negros, traje blanco de lino. Ordena desalojar la capilla de Malverde, para hablar a solas directamente con él, solicitándole ayuda para dominar otros territorios: Juárez, Tamaulipas, Guerrero, USA.

En su monólogo interior recuerda cómo al confiarse, la DEA detectó sus sembradíos en la sierra; pero asesina al de la DEA. Se desata su persecución, un competidor se alía con el gobierno para tumbarle la plaza. Hace un paralelismo con el "santo", de cómo eludió a los "guachos", enviados tras él. Descripción geográfica y de la flora de la sierra, como sus ayudantes, como sus protectores. En tanto el ejército arremete contra la población pacífica con saña. Gracias a Malverde no lo encuentran y puede vengarse de sus enemigos, que propiciaran su persecución.

\section{IV $^{\circ}$ TIEMPO}

LEONEL: hace el recuento del asesinato de sus hermanos por matones disfrazados de "guachos", encabezados por el del Traje Blanco. Los informantes de la sierra son gomeros-agricultores. Concluye su petición y su relato. Al retirarse recuerda no haber dejado limosna al santo y al regresar se percata de que 40 pistoleros vestidos como miembros de la FIS llegan a la capilla protegiendo a Julio, quien 
se aparece en la capilla de blanco como palomo en "una Lincoln".

A continuación, en los siguientes tiempos, Román entrelaza las tres historias, los tres destinos, de estos narcotraficantes ese 3 de mayo en la capilla de Malverde. Historias que siguen desarrollándose bajo el flujo del pensamiento en medio del festejo con cervezas, y la música de la tambora que ruidosamente lanza al aire las notas del "Sinaloense", el corrido emblemático del narco; en tanto se acribillan.

De esta manera el autor construye, hace, un relato de la cultura del narcotráfico, a través de las inicialmente historias personales, individuales, aparentemente sin relación alguna; excepto la temática del narcotráfico como hilo conductor. Historias que posteriormente van develándose, entrelazándose. Mostrándonos así la rivalidad y la competencia entre los diversos cárteles en su lucha a muerte por el mercado y producción de la droga; como ocurre en la realidad actual, conducente al ajuste de cuentas entre éstos.

Por ello no resulta difícil identificar los protagonistas individuales, ni a los grupos a que pertenecen, provocadores de la narcoviolencia en su lucha por dominar el tráfico de drogas; ya que Román ha construido su texto a partir de hechos concretos y públicos. Por lo que los ajustes de cuentas presentes en su relato dramático no resultan de una metaficcionalización, sino la representación de la violencia misma, provocada por el narcoterrorismo; dando como resultado el asesinato de miles de personas, como lo señalan las estadísticas más recientes hechas públicas por la prensa.

Como podemos ver los personajes de Román no tienen relación alguna con la causa popular, ni Malverde tiene el sentido social que se le atribuía como héroe, ya que al convertirlo el narcotráfico en su protector, se le ha conferido poder mágico propiciatorio nulificando así al Malverde mitificado, al desvanecerse su rebeldía vindicadora, al predominar su lado oscuro, señalado por Yépez.

Si consideramos las premisas planteadas por Selligson, Harmony, Galicia y Román en su entrevista con Sierra, encontraremos que el Malverde de la obra de Liera, en la que se expone un supuesto proceso de beatificación, sólo es un referente para mostrárnoslo en el espacio interior donde se desarrolla el relato mítico de éste, no sólo como héroe reparador de las injusticias sociales, y del abuso del poder de los gobernantes de aquella época; sino también como ejecutor, como instrumento de las aspiraciones del pueblo sinaloense a través de las andanzas y hazañas del protagonista.

Narratema, mediante el cuál Liera expresara también su rechazo a los usos y costumbres del momento; impuestos por el poder político del 
Estado - como anteriormente ha sido señalado - , por medio del relato de los informantes del espacio exterior. Actantes convertidos en razonadores del autor para denunciar abiertamente al mal gobierno sinaloense y del país y, con ello, condenar los abusos de las clases dominantes: la burguesía, los gobernantes y el clero, socios tradicionales de todos los tiempos.

En tanto al Malverde de Román los narcotraficantes al haberse apropiado del héroe vindicador del pueblo ya lo han convertido en cómplice milagroso; dándole así un nuevo sentido a su narratema, a su mito inconcluso; al haber sido despojado del significado inicial que el pueblo le confiriese en su deseo de alcanzar la justicia, en un mundo que le fuese adverso.

Por lo que en el referente de Román no se encuentran las causas populares, ni el sentido social que se le atribuía a Malverde como héroe mítico; al haber sido nulificado como tal, al pasar a la categoría de protector por obra y gracia del narcotráfico, en su faceta de héroe "malvado", y ya no como imagen de la rebeldía del pueblo; al habérsele conferido poder mágico, al invocarlo para que les sea propicio en sus fechorías, invalidando así su categoría de santo popular.

Asunto central desarrollado en su Malverde a través del relato y del monólogo interior de los antihéroes protagonistas, que han invadido el panorama nacional, y ante los cuales se encuentran desarmados tanto el poder civil como el militar.

Como el propio autor lo afirma:

La línea desarrollada por Román — autor de obra como Mastercard — traza una crónica desde la metáfora del arte. "Todo parece que es nota roja, pero finalmente son hechos que se van a convertir en datos históricos." (Sierra F3)

Una crónica no sólo sobre la cultura del narcotráfico, sino además sobre los protagonistas del relato dramático a través de su comportamiento, sus motivaciones y su proceder, que han contaminado, infestado, el tejido de la vida social, económica y civil, tanto del ámbito del campo como del urbano, de todo el país; al haberse convertido el tema del narcotráfico en sujeto de la acción dramática en las obras de este dramaturgo.

Es por ello que de hecho nos encontramos con una crónica sobre la cotidianidad de los narcos, como secuela de la descomposición social del país en el que la cultura del narcotráfico se ha convertido en este relato dramático en una ensoñación del onirismo narco, en el que predomina la diégesis sobre la mimesis. De manera que el texto dramático de Alejandro Román resulte la crónica de los sucesos recientes, determinada por los hechos sangrientos 
que en los últimos tiempos han teñido al mapa nacional. De allí que su texto podemos considerarlo con un non-fiction-drama, sin divagación alguna de orden ficcional; ${ }^{21}$ por la naturaleza del relato dramático como testimonio realista del discurrir de los protagonistas, cuya realidad está determinada por la violencia, las balas y la sangre derramada con que se ha teñido el territorio nacional, como si éste fuese sólo un escenario, y nada más, para su lucha a muerte por el dominio de territorios de influencia; mismos que se han convertido en playground para la ejecución de sus acciones delictivas.

De allí que los personajes de Román no se relacionen con la causa popular, ni su Malverde tenga el sentido social que inicialmente se le atribuyese como héroe, como bandido generoso; ya que al haberse apoderado el narcotráfico del protector familiar, del protector de los pobres y desamparados, se ha nulificado la faceta del Malverde mitificado, al habérsele despojado de su rebeldía vindicadora y su aureola de santón; al haberlo puesto a su misma altura de capo protector, al invocar a la naturaleza mágica negativa de su persona; convirtiéndolo así en leyenda urbana, con la cual éstos se identifican del todo.

De manera el Malverde mítico de El jinete de la Divina Providencia responde altruistamente - en una primera instancia —, gracias a las aspiraciones de quienes acuden tanto a éste, como a su capilla - convertida en un lugar de convivencia social - , ante la imposibilidad de poder viajar a la Villa de Guadalupe - primer mito fundacional de nuestra mexicanidad para cumplir con la promesa de visitar su santuario una vez obtenido su favor. En una segunda instancia, Malverde ha sido despojado de su ropaje, de su rol como benefactor, como santo, por un interés egoísta de los narcotraficantes que se lo han apropiado para poder realizar sus fechorías en su lucha descarnada al identificarse sólo con su lado oscuro, en el rol de bandido.

$\mathrm{Al}$ respecto, John Lash en su The Hero: Manhood and Power plantea sobre el héroe mítico y el santo lo siguiente:

Myth and history preserve the names of many men regarded as heroes, an abundance of figures who seem to have attained a superhuman stature. Almost anyone can act heroically [...]. He possesses a consistent capacity for action that surpasses the norm of man or woman. [...] The hero is, in his prime, fully human rather than superhuman. A rare configuration of traits and striking style of action mark him as having arête, excellence. In excelling and exceeding himself, the hero becomes a model of higher potential for the clan, his race or nation, even for humanity at large. (5) 
A esta categoría de héroe pertenece el Malverde de Liera; en tanto en el de Román predominan las otras características del héroe mítico:

Gender is an issue here, for ideally the hero incarnates masculinity in its best, most noble aspects, even though he is potentially equal to the worst of which his sex is capable. His career is turbulent and controversial because virility is close kin of violence-perhaps even its dark, unruly twin. In all cultures, the hero is uniquely charged with the responsibility to use violent force, as the situation requires, without being consumed by it [...] (Las cursivas son nuestras, APT). (5) Masculinidad negativa con la que los narcos han contaminado a Malverde al identificarlo como su igual; aunque éste no sea quien ejerza la maldad.

Así mismo Lash considera tres variantes del héroe:

The sage and the saint, or savoir, commonly treated as variants of the hero, are really deviants from his pure and primary masculine types - sage, saviour and warrior-hero arise from different origins and reflect conflicting ideologies of power. Deeply implicated in problems of power, the hero on his true calling never uses it to dominate others. Heroes fight their equals, other heroes, or take on monstrous adversaries, but to challenge or overpower ordinary people is beneath them. The mission of the hero in all his variants consists not merely in the management of the force, but in the mastery of an excess of force. His challenge is to face forces gone out of control, exceeding their proper limits, and he himself embodies the dangerous superfluity of such forces. (6)

Si bien a este héroe-guerrero lo podemos identificar con el Malverde al que se refiere Liera; si lo consideramos como un mito, como un constructo socio cultural, encontraremos que conforme cambian los tiempos, también cambia su persona y se transforma el mito, al igual que la naturaleza del héroe:

The Ever-changing Quest. Rather like a chameleon, the hero changes with his surroundings, his time and his sociocultural environment. As a medium and moving index of our common experience, he is susceptible to being overwhelmed by the very conditions he reflects, especially when these conditions become hugely or grotesquely magnified so that the moral orientation of the hero to his situation in difficult, if not impossible, to discern. (17)

De allí que, desde la perspectiva de lo asentado anteriormente por Yépez y Lash, sobre el narratema y el mito, el héroe-luchador; al igual que la transformación de este en santo popular, podemos concluir que el paso del 
mito heroico sobre el Malverde del dramaturgo Óscar Liera, al de protectorsantón de Alejandro Román, éste es el resultado de la resignificación de la figura mítica, debido a los propios cambios que ha sufrido la realidad nacional.

Finalmente, ¿qué es lo que ha determinado socio-culturalmente ese paso sobre el cual se cuestiona Olga Harmony, sobre esa transformación, ese trasvase de un constructo cultural a otro? La única razón que encontramos es la de que al haberse alejado el sistema ejecutivo, legislativo y judicial de sus funciones consustanciales y de su esencia significativa; al igual que el sistema de derecho, éstos se desvirtuaron e instituyeron en sólo un simulacro al servicio del poder político durante siete décadas para conservar su hegemonía; mismas prácticas que se han seguido en los dos últimos sexenios gubernamentales, al haber éstos adoptado los mismos vicios y costumbres del partido anterior en el poder; aunando a esto su ineficacia y complicidad, que han propiciado este cambio de sentido a la imagen de Malverde.

Razón por la cual dicho simulacro instauró la cultura de la ilegalidad, de la corrupción, del soborno, de la extorsión, del lavado de dinero, de la violencia, de la impunidad, de la inseguridad, de la delincuencia, del crimen, de los secuestros, de la narcocorrupción, de las ejecuciones, de las masacres perpetradas por los sicarios de los cárteles del narcotráfico y la colusión del crimen organizado en las instituciones del Estado, que mantienen en vilo al país; como resultado de la descomposición y deterioro del tejido social y público nacional, desencadenados por la impunidad y la ausencia de la ley.

De allí que la dramatización de Alejandro Román sea la crónica de nuestros tiempos sangrientos, en la que la leyenda urbana de Malverde se ha entronizado en la cultura del narcotráfico como su santo protector.

\section{Colegio de Literatura Dramática y Teatro \\ Facultad de Filosofia y Letras / UNAM}

\section{Notas}

1 Primera publicación: suplemento de Escénica, revista de teatro de la UNAM, época I, número 10, enero-marzo, presentación Esther Seligson, 20 pp. Segunda publicación: El jinete de la Divina Providencia. Culiacán: UAS, 1987. 65 pp. Tercera publicación: Óscar Liera. Teatro Completo, tomo II (estudio introductorio: Armando Partida; investigación y notas: Armando Partida y Sergio López). Culiacán: SEPYS/ Cobaes/ Difocur, 1997. 130-77.

Estrenada por el Tatuas el 7 de julio de 1984 en el Foro de la Casa de la Cultura de la UAS, en la ciudad de Culiacán, Sinaloa, dirigida por el autor. Ese mismo año participó en la Muestra Nacional 
de Teatro realizada en la ciudad de Jalapa, Veracruz, al igual que posteriormente en la reanudación del Festival de Manizales, Colombia. Al año siguiente se presentó en el Festival Latino de Nueva York. Fue llevada al cine en 1988 por Óscar Blancarte.

2 El Víctor Hugo Rascón Banda de la Universidad Autónoma de Nuevo León en 2006, el Óscar Liera de Sinaloa en 2007, el Fernando Sánchez Mayans en Campeche, también en 2007 y, de nuevo, el Óscar Liera en este año de 2008.

3 Esther Seligson, "Unir los sueños, juntar los juegos". El jinete de la Divina Providencia, Presentación a Escénica, Revista de Teatro UNAM, Época I núm. 10, Ene-mar 1985, Suplemento.

4 Frase pronunciada por uno de los informantes: Martha / y personaje: Adela (APT).

5 Referencia a una de las expresiones repetidas por el autor culiacanense en otras obras (APT).

6 Rocío Galicia, Ánimas y santones, Vida y milagros del Niño Fidencio, el Tiradito y Malverde, antología dramática, Compiladora. Libros de Godot, INBA, CNCA, CITRU, México, 2008, pp. 135-97 (Teatro ExCéntrico).

7 Al igual que en su El oro de la Revolución mexicana (1984), lo mismo que la mención de algunos de sus herederos en Cuchara y Mácara (1977) (APT).

8 Francisco Cañedo Belmonte (1840-1909). Combatió la intervención francesa y el imperio. Se adhirió al alzamiento de Tuxtepec. Durante el porfiriato llegó a general, fue senador por Sinaloa y gobernador del estado en varias ocasiones. Fue procesado por el asesinato del periodista José Cayetano Valdés y lo absolvió el Gran Jurado. Ofreció una cuantiosa recompensa por Heraclio Bernal, quien lo combatió durante muchos años (Musacchio, Diccionario enciclopédico de México A-D 276-77).

9 Antonio Toledo Corro (1919). Político y empresario. Pertenece al PRI, en el que ha sido secretario general en Sinaloa (1951), diputado de la Legislatura de esa entidad (1951-53), presidente de la Cámara de Comercio de Sinaloa (1957), presidente municipal de Mazatlán (1960-63), encargado de mecanización de zonas ajidales de Campeche (1970), diputado federal (1976-1977), gerente general de Servicios Ejidales SA (1977), secretario de la Reforma agraria (9 de junio de 1978 al 28 de abril de 1980) en el gobierno de José López Portillo y gobernador de Sinaloa (primero de enero de 1981 al 31 de diciembre de 1987) (Musacchio, Gran Diccionario Enciclopédico de México Visual: R-Z 2041).

${ }^{10}$ Especie silvestre de arbusto espinoso, abundante en los breñales (APT).

${ }_{11}$ Pueblos cercanos a Culiacán, algunos de los nombres proceden de la lengua que hablaban los pobladores nativos de la región (APT).

${ }_{12}$ De donde supuestamente fuera colgado Malverde (APT).

${ }_{13}$ Personaje de la vida real, en cuya fábrica se elaboraron las primeras telas de mezclilla, que se enviaba a la Alta California para la elaboración de la ropa para mineros (APT).

${ }^{14}$ La tambora, es un conjunto musical regional muy popular en Sinaloa, estado en el que se prefiere la ingesta de cerveza sobre todas las bebidas embriagantes, en la que los destilados, incluso el tequila, no tienen gran mercado, sobre todo en las clases populares (APT).

${ }_{15}$ Pieza musical que sostiene un diálogo entre dos trompetas distantes, que simbolizan mediante el reclamo de éstas la búsqueda del "niño perdido", que responde al llamado. Misma que en la pieza de Liera sirve para atemorizar al mal gobernante, como amenaza de su muerte, que se repite como un ritornelo en el espacio interior donde se desarrollan los hechos pasados, a los que se hacen remembranza en el espacio exterior (APT).

${ }^{16}$ El loco premonitorio del pueblo. Personaje que para Liera resultara una constante en la vida cotidiana de Culiacán, como en una réplica lo hace saber el Obispo: "Pero si Culiacán no ha sido más que un pueblo de locos". Personajes por los cuales Liera sintiera gran atracción; al igual que por los cirqueros y maromeros (APT).

${ }_{17}$ Planta que exuda una goma (Familia apocináceas) (APT).

${ }^{18}$ Liebres, en la lengua regional cahita (APT).

19 Nombre que posiblemente Liera tomara de un restaurante parisino de comida tradicional francesa, localizado en el Barrio Latino, muy cerca del Teatro Odeon (APT). 
${ }^{20}$ Cf., Guillermo Bonfil Batalla, México profundo. Una civilización negada. "Las estrategias cotidianas". 190-200.

${ }^{21}$ En el discurrir de Gavilán nos enteramos de cómo fue acribillado por los sicarios que asesinaran al narcojúnior que custodiara. Circunstancia del todo cotidiana dentro de la cultura del narcotráfico, como la ocurrida con Edgar Guzmán, ejecutado en Culiacán el 08.05.08, hijo del famoso Chapo, evadido de un penal de alta seguridad, y aún prófugo. "Redacción: En internet y en su vida diaria, Edgar Guzmán presumía el poderío del ídolo que tuvo en sus dos décadas de vida: su padre Joaquín El Chapo Guzmán, líder del cártel de Sinaloa. / Aficionado a internet, Edgar ingresaba con su propio nombre a blogs para defender al cártel de Sinaloa, hablar sobre los territorios conquistados por su padre y afirmar que el resto de los cárteles no desplazarían la posición ganada por El Chapo. / El menor de los hijos de El Chapo Guzmán repetía a los cibernautas que 'Sinaloa es tierra de puros hombres', y en gran parte de sus mensajes vitoreaba a su padre: 'arriba el cártel de Sinaloa, putos, arriba El Chapo Guzmán'. / Pero Edgar también era protagonista de canciones y videos en internet. / Las letras de los corridos que pueden consultarse en internet describen el estilo de vida de Edgar Guzmán, su profundo respeto a su madre y su admiración por su padre. / 'Por las calles de las presas, allá en las quintas famosas. Edgar Guzmán se paseaba en camionetas lujosas. Rodeado de sus amigos y muchachas muy hermosas en Culiacán, Sinaloa, sube y baja en sus aviones,' señalan las primeras estrofas de uno de sus corridos con su nombre [e imagen en video, trasmitidos por YouTube Online]. / A manera biográfica, la letra sigue: 'Edgar dice a sus hermanos nuestro padre lo ha heredado, ya traemos en la sangre ser hombres y respetados. No presume su apellido, y se la da de valiente, pero si rifa el cuero no se vale de su gente. Ni por ser un heredero, no se lo deja a su suerte, Edgar es hombre de honor, hijo del Chapo Guzmán.' / Sus amigos colocaban también en diferentes blogs las canciones sobre Edgar interpretadas por los gruperos profesionales o amateurs. / Adolescentes de diferentes lugares de México y del extranjero le enviaban mensajes a Edgar e incluso fotografías. / Antes de la balacera del jueves, hubo dos intentos recientes para matar a Edgar Guzmán, uno durante un tiroteo en la discoteca Bilbao, presuntamente propiedad de Arturo Cázarez, hijo de la llamada Emperatriz del cártel de Sinaloa, y otra balacera más en la discoteca Maxíms, ambos ubicados (sic) en Culiacán. / Pero Edgar, afirman cercanos, no se dejaba amedrentar por nada, confiaba en que el poderío de su padre era suficiente para controlar todo negocio en el país, es por ello que mantenía sus viajes por Sinaloa, pero sobre todo por Badirahuato y por Culiacán donde fue balaceado. (El Universal, 10.15.08)

\section{Obras citadas}

Bonfil Batalla, Guillermo. "Las estrategias cotidianas". En México profundo, Una civilización negada. México: CIESAS / SEP, 1987 (Foro 2000). 190-200.

Campbell, Joseph. El héroe de las mil caras, psicoanálisis del mito. México: FCE, 1997.

Galicia, Rocío. Malverde. En Ánimas y Santones, Vida y milagros del Niño Fidencio, el Tiradito y Malverde, antología dramática. Compiladora. México: Libros de Godot, INBA, CNCA, CITRU, 2008, (Teatro Ex Céntrico). 135-97.

Harmony, Olga. "Máscaras y visiones encontradas". La Jornada Cultural 10 de julio $08: 6^{\mathrm{a}}$.

Lash, John. The Hero: Manhood and Power. London: Thames and Hudson Ltd, 1995. Liera, Óscar. El jinete de la Divina Providencia. En Óscar Liera, Teatro Escogido. México: FCE, Fondo Regional para la Cultura y las Artes del Noroeste, 2008 (Letras Mexicanas). 359-401. 
Musacchio, Humberto. Gran diccionario enciclopédico de México Visual A-D. México: Andrés León editor, 1990.

---. Gran diccionario enciclopédico de México Visual R-Z. México: Andrés León editor, 1990.

"Narcojúnior y bloguero". El Universal 10 de mayo 08: A9.

Román, Alejandro. Cielo Rojo. Monterrey: Universidad Autónoma de Nuevo León, 2007.

---.Coca Light. En La ciudad en el teatro. Selección y prólogo de Víctor Hugo Rascón Banda. México: Juan Pablos, Secretaría de Cultura del Gobierno del Distrito Federal, 2002. 353-89.

---. Línea de fuego. México: Paso de Gato, 1987 (Cuadernos de Dramaturgia Mexicana 12).

Seligson, Esther. "Unir los sueños, juntar los juegos". Escénica I.10 (Ene-mar 1985): Suplemento.

Sierra, Sonia. "Malverde, ahora una metáfora escénica". El Universal 22 de ago. 08: F3. 
